Alexander Tsivian · Menahem Neuman • Oded Kessler • Baruch Mogutin · Doron Korczak · Samuel Levin • A. Ami Sidi

\title{
Does patient weight influence the outcome of the tension-free vaginal tape procedure?
}

\section{A long-term follow-up study}

Received: 18 March 2006 / Accepted: 7 May 2006 / Published online: 11 July 2006

(C) Springer-Verlag Berlin / Heidelberg 2006

\begin{abstract}
Urinary stress incontinence (USI) is more common in obese women. The influence of obesity on surgical treatment for USI is controversial. We sought to determine whether obesity affects the outcome of the tension-free vaginal tape (TVT) procedure. The retrospective data of 81 women that underwent the TVT procedure between 04/1998 and 12/2000 were studied. The study cohort women (aged 37-87 years) were subdivided into three groups according to body mass index (BMI): normal (BMI $=<25)$-group 1, overweight $(\mathrm{BMI}=25-29)-$ group 2 , and obese $(\mathrm{BMI}=>30)$ group 3. All women underwent preoperative examinations, including detailed medical history and physical examination with stress tests and urodynamic studies. Follow-up included post-procedure check-up meetings at 1, 3, 6, and 12 months and once yearly thereafter (minimal follow-up $=52$ months). Intra- and postoperative complications and success rates were compared among the three groups. Twenty-six (32.1\%) women had
\end{abstract}

A. Tsivian · O. Kessler · B. Mogutin ·

D. Korczak · S. Levin · A. A. Sidi

Department of Urologic Surgery,

Edith Wolfson Medical Center,

Holon, Israel

A. Tsivian · O. Kessler $\cdot$ B. Mogutin ·

D. Korczak $\cdot$ S. Levin $\cdot$ A. A. Sidi

Department of Urologic Surgery,

Sackler Faculty of Medicine, Tel Aviv University,

Tel Aviv, Israel

M. Neuman $(\bowtie)$

Urogynecology, Department of Obstetrics and Gynecology, Shaare-Zedec Medical Center,

Jerusalem, Israel

e-mail: mneuman@netvision.net.il

Tel.: +972-522-276800

Fax: $+972-8-9287983$

M. Neuman

Department of Obstetrics and Gynecology,

Ben Gurion University of the Negev,

Negev, Israel normal BMI, 21 (25.9\%) were overweight, and 34 (42\%) were obese. Six intraoperative complications were recorded, including 5 bladder injuries and 1 urethral injury, none of which required surgical re-intervention. Eight reported postoperative complications included 1 bladder erosion, 3 urethral obstructions, 4 vaginal erosions (1 patient suffered from concomitant urethral obstruction and vaginal erosion). Five patients diagnosed with postoperative surgical complications underwent corrective surgery. There were no significant intergroup differences among the complication rates. The success rates were $84.6 \%, 81 \%$, and $79.4 \%$ in groups 1 , 2 , and 3 respectively. Increased BMI may have a slight negative impact on TVT results, but the long-term success rate of $79.4 \%$ in obese women and the lack of any direct correlation between BMI and complications sanction their undergoing TVT.

Keywords Obesity · Urinary stress incontinence · TVT

\section{Introduction}

Urinary stress incontinence (USI) is more common in obese women [1]. The influence of obesity on the outcome of surgical treatment is unclear. While some authors report high failure and postoperative complication rates [2, 3], others do not consider obesity to be a risk factor with regard to failure or surgical complications $[4,5]$.

Tension-free vaginal tape (TVT) is a relatively new procedure [6], but is already widely used for the surgical treatment of female USI. The aim of this study was to determine the impact of obesity on the outcome and complication rate of TVT procedures with a minimal follow-up of more than 4 years.

\section{Materials and methods}

The complete medical records for 81 out of 90 women who underwent a TVT procedure in our department between 
April 1998 and December 2000 were obtained and studied. Body mass index (BMI, $\mathrm{kg} / \mathrm{m}^{2}$ ) was calculated for each woman at the time of surgery, and the subjects were subdivided into three groups according to their BMI: normal $(\mathrm{BMI}=<25)$ - group 1, overweight $(\mathrm{BMI}=25-29)$ group 2, and obese (BMI $=>30)$-group 3. Nine patients were lost to follow-up (2, 3, and 4 patients in groups 1,2 , and 3 respectively). All women underwent preoperative examination, including detailed medical history and physical examinations with stress tests and urodynamic studies. Seventeen patients had undergone previous hysterectomy and 11 had undergone previous anti-incontinence procedures (Table 1). All TVT procedures were performed according to Ulmsten's method [6]. Fifty-three patients underwent concomitantly various other vaginal reconstructive procedures, including vaginal hysterectomy, anterior and posterior colporrhaphy, and vaginal vault suspension.

Follow-up included interview and physical examinations (including stress test) at $1,3,6$, and 12 months following the TVT procedure and a telephone survey using a questionnaire (UDI-6, short form) [7] thereafter. Intraand postoperative complications and success rates were compared among the three groups. Analysis of data was carried out using SPSS statistical analysis software (SPSS, Chicago, IL, USA). Inter-group outcome variables were compared using the Chi-squared test with $99 \%$ Monte Carlo confidence intervals or Fisher's exact test when expected frequencies were low. All tests were two-sided and considered significant at $p<0.05$.

The criteria for therapeutic success were complete continence and freedom from the need for pad protection; all other outcomes were classified as failures. The minimum follow-up for study suitability was 52 months.

\section{Results}

Of the 81 study group patients, aged 37-87 years, 26 (32.1\%) had normal BMI, 21 (25.9\%) were overweight, and $34(42 \%)$ were obese (Table 1). Twenty-eight women $(34.6 \%)$ underwent only the TVT procedure and 53 $(65.4 \%)$ underwent concomitant vaginal surgery, including (one or more) hysterectomy $(n=3,3.7 \%)$, anterior colporrhaphy $(n=25,30.6 \%)$, posterior colporrhaphy $(n=42$, $51.9 \%)$, and vaginal vault suspension $(n=2,2.5 \%$; Table 2). Anesthesia was local $(n=2,2.47 \%)$, spinal $(n=41,50.6 \%)$ or general $(n=38,46.9 \%)$; no differences were found within the three patient groups regarding both baseline characteristics and success rates. Data on complications and success rates were tabulated and are displayed in Table 3. The patients were followed for $52-$ 84 months (median 65 months). No cases of wound infection were recorded. Five women $(6.2 \%)$ underwent corrective surgery for complications: 2 needed tape incision for urethral obstruction [8], 1 needed the removal of an eroded part of the tape from the bladder [9], and 2 needed partial tape removal on the grounds of vaginal erosion. One patient with asymptomatic vaginal erosion is being treated expectantly and another patient with concomitant vaginal erosion and partial urethral obstruction refused corrective surgery.

There were no significant differences in intra- or postoperative complication rates among the groups. The statistical breakdown for each complication was as follows: bladder perforation $p=0.6$, urethral injury $p=0.3$, short-term voiding difficulties $p=0.08$, urethral obstruction $p=0.2$, urgency de novo $p=0.7$, bladder erosion $p=0.5$, vaginal erosion $p=0.9$. With the exception of short-term voiding difficulties, the complications we evaluated occurred infrequently in the study population as a whole. The overall combined subjective and objective success rates, based on the UDI-6 (short form) questionnaire and clinical stress tests were $84.6 \%, 81 \%$, and $79.4 \%$ in groups 1,2 and 3 respectively, with an overall success rate of $81.5 \%(p=0.9)$. The success rate was stable throughout the review period and did not decline over time.

\section{Discussion}

Increased BMI has been studied as both a risk factor for developing incontinence and as an explanation for failed corrective surgery. Burgio et al. [10] found a direct correlation between increased BMI and the presence of urinary incontinence. Rasmussen et al. [11] compared obese women (BMI $>30)$ with controls $(\mathrm{BMI}<25)$ before, during, and up to 18 months after pregnancy and found a higher incidence of USI in the obese group than in the control group at all three time points.

The literature on the influence of being overweight on outcome of anti-incontinence surgery is conflicting. Gillon et al. [4] found that increased body mass did not affect the results of the Burch procedure, but that it did not facilitate surgical maneuverability either. Cummings et al. [12] reviewed the records of 16 women with morbid obesity who underwent bladder neck suspension (4 cases) and sling procedure (12 cases). The authors noted that the

Table 1 Demographic data of the study population. $B M I$ body mass index, $M M K$ Marshall-Marchetti-Krantz, $A C$ anterior colporrhaphy

\begin{tabular}{|c|c|c|c|c|c|c|c|c|}
\hline \multirow[t]{2}{*}{ BMI groups } & \multirow[t]{2}{*}{ Patients } & \multirow[t]{2}{*}{ Mean age (years) } & \multicolumn{2}{|c|}{ Previous hysterectomy } & \multicolumn{4}{|c|}{ Previous anti-incontinence procedure } \\
\hline & & & Transabdominal & Transvaginal & Burch & Raz & MMK & $\mathrm{AC}$ \\
\hline 1 & 26 & 61.9 & 4 & 1 & 3 & 1 & 0 & 0 \\
\hline 2 & 21 & 65.8 & 3 & 1 & 1 & 1 & 0 & 1 \\
\hline 3 & 34 & 63.1 & 6 & 2 & 1 & 0 & 1 & 2 \\
\hline Total & 81 & 63.4 & 13 & 4 & 5 & 2 & 1 & 3 \\
\hline
\end{tabular}


Table 2 Concomitant procedures

\begin{tabular}{lcccccc}
\hline BMI groups & Patients & TVT only & Transvaginal hysterectomy & Anterior colporrhaphy & Posterior colporrhaphy & Vault prolapse repair \\
\hline 1 & 26 & 10 & 2 & 9 & 12 & 1 \\
2 & 21 & 8 & 1 & 10 & 20 & 0 \\
3 & 34 & 10 & 3 & 25 & 42 & 1 \\
Total & 81 & 28 & 0 & 6 & 2 \\
\hline
\end{tabular}

operations were somewhat more difficult to perform due to the body habitus of these patients, particularly the harvesting of the rectus fascia. In their series, two bladder neck suspensions failed, but all the sling procedures were successful. They concluded that morbidly obese women with USI can undergo operations for this disorder with a good chance for success, and that the sling operation may be the procedure of choice for this population. Brieger and Korda [2] reported an increased failure rate among obese women who underwent bladder neck needle suspension and retropubic procedures. O'Sullivan et al. [3] demonstrated poor outcomes in obese women who underwent needle suspension. According to a recent publication by Lovatsis et al. [13], the traditional surgeries have variable success rates in these women, are more technically difficult, and may carry increased morbidity. Zivkovic et al. [5] reported that the continence rates at 5-year follow-up for anterior colporrhaphy, anterior colporrhaphy with needle suspension of the bladder neck, and Burch colposuspension were $58 \%, 51 \%$, and $86 \%$ respectively. The continence rate did not differ significantly among the three BMI groups for each procedure [5]. Alcalay et al. [14] reported that preoperative weight of more than $80 \mathrm{~kg}$ adversely affects the continence rates for Burch colposuspension after 10-20 years' follow-up.

The TVT procedure is a novel modality for managing female urinary stress incontinence [6]. It has been rapidly gaining popularity worldwide. Recent studies reported high cure rates of $78.9 \%$ to $84.7 \%$ after long-term follow-up $[15,16]$ and described relatively low intraoperative and postoperative complication rates [17]. However, there are few published short-term studies on the outcomes of the TVT procedure in overweight and obese women $[13,18-20]$. Chung et al. retrospectively compared the efficacy and safety of 91 cases of TVT procedures and 51 laparoscopic Burch procedures. Their findings indicated that TVT is a safer, more effective, easier, and less invasive surgery for USI regardless of the patient's BMI and that it favorably compares with the laparoscopic Burch procedure, which requires advanced surgical skills [18]. Lovatsis et al.'s data [13] did not demonstrate any difference in cure rate of the TVT procedure between obese and non-obese patients. Given the finding of fewer complications, the authors suggested that this procedure might be an ideal surgical treatment modality for USI in obese women [13]. Mukherjee and Constantine [19] compared the data of 242 women who underwent the TVT procedure with a follow-up of 6 months. The cure rate was $85 \%$ in women with BMI $<25,95 \%$ in women with BMI $25-29$, and $89 \%$ in women with BMI $>30$. There was no significant difference in the numbers of complications among the obese and the other groups, and the authors concluded that the TVT procedure is at least as effective in obese as in non-obese women; hence, this might be offered confidently to obese women with USI [19]. Rafii et al. [20] compared the TVT procedure in 38 patients with BMI $>30$ and 149 patients with BMI $<30$. Obesity was not found to be a risk factor for failure of the procedure, yet the mixed incontinence and procedure failure rates were significantly higher in the obese group. The incidence of postoperative de novo urgency was $25 \%$ in the study group.

It is noteworthy that most ( 55 out of $81,67.9 \%$ ) of the patients in our series were overweight or obese. In our study as with that of Rafii et al. [20] the incidence of de novo urgency was relatively high (above $23 \%$ ) among the overweight and obese women.

The limitations of the current study are its retrospective design, the relatively small sample size, and the fact that $10 \%$ of the patients were lost to follow-up. The strength of this study is the long period of review (more than 52 months).

\section{Conclusions}

In this first study on long-term ( $>52$ months) postoperative results, we demonstrated that an increase in BMI appears to have a slightly negative impact on the outcome of the TVT

Table 3 Operative complications

\begin{tabular}{lccccccccc}
\hline $\begin{array}{l}\text { BMI } \\
\text { groups }\end{array}$ & $\begin{array}{c}\text { Patients } \begin{array}{l}\text { Bladder } \\
\text { perforation }\end{array} \\
\text { injury }\end{array}$ & $\begin{array}{l}\text { Urethral } \\
\text { (catheter 2-6 days) }\end{array}$ & $\begin{array}{l}\text { Short-term voiding difficulties } \\
\text { obstruction }\end{array}$ & $\begin{array}{l}\text { Postoperative de } \\
\text { novo urgency }\end{array}$ & $\begin{array}{l}\text { Bladder } \\
\text { erosion }\end{array}$ & $\begin{array}{l}\text { Vaginal } \\
\text { erosion }\end{array}$ & $\begin{array}{l}\text { Cure } \\
\text { rate (\%) }\end{array}$ \\
\hline 1 & 26 & 2 & 1 & 11 & 1 & $4(15.4 \%)$ & 0 & 1 & 84.6 \\
2 & 21 & 2 & 0 & 11 & 2 & $5(23.8 \%)$ & 0 & 1 & 81 \\
3 & 34 & 1 & 0 & 8 & 0 & $8(23.5 \%)$ & 1 & 2 & 79.4 \\
Total & 81 & 5 & 1 & 30 & 3 & 17 & 1 & 4 & 81.5 \\
\hline
\end{tabular}


procedure. The success rate of $79.4 \%$ in a population of obese women and no direct correlation between BMI and surgical complications sanction this procedure to be carried out in them.

Acknowledgement Esther Eshkol is thanked for editorial assistance.

\section{References}

1. Dwyer PL, Lee ET, Hay DM (1988) Obesity and urinary incontinence in women. Br J Obstet Gynaecol 95:91-96

2. Brieger G, Korda A (1992) The effect of obesity on the outcome of successful surgery for genuine stress incontinence. Aust NZ Obstet Gynaecol 32:71-72

3. O'Sullivan DC, Chilton CP, Munson KW (1995) Should Stamey colposuspension be our primary surgery for stress incontinence? Br J Urol 75:457-460

4. Gillon G, Engelstein D, Servadio C (1992) Risk factors and their effect on the results of Burch colposuspension for urinary stress incontinence. Isr J Med Sci 28:354-356

5. Zivkovic F, Tamussino K, Pieber D, Haas J (1999) Body mass index and outcome of incontinence surgery. Obstet Gynecol 93: 753-756

6. Ulmsten U, Henriksson L, Johnson P, Varhos G (1996) An ambulatory surgical procedure under local anesthesia for treatment of female urinary incontinence. Int Urogynecol J Pelvic Floor Dysfunct 7:81-85

7. Uebersax JS, Wyman JF, Shumaker SA, McClish DK, Fantl JA (1995) Short forms to assess life quality and symptom distress for urinary incontinence in women: the incontinence impact questionnaire and the urogenital distress inventory. Neurourol Urodyn 14:131-139

8. Neuman M (2004) Post tension-free vaginal tape voiding difficulties - prevention and management. J Pelvic Med Surg 10:19-21
9. Neuman M (2004) Tension-free vaginal tape bladder penetration and long-lasting transvesical prolene material. J Pelvic Med Surg 10:307-309

10. Burgio KL, Matthews KA, Engel BT (1991) Prevalence, incidence and correlates of urinary incontinence in healthy, middle-aged women. J Urol 146:1255-1259

11. Rasmussen KL, Krue S, Johansson LE, Knudsen HJ, Agger AO (1997) Obesity as a predictor of postpartum urinary symptoms. Acta Obstet Gynecol Scand 76:359-362

12. Cummings JM, Boullier JA, Parra RO (1998) Surgical correction of stress incontinence in morbidly obese women. J Urol 160:754-755

13. Lovatsis D, Gupta C, Dean E, Lee F (2003) Tension-free vaginal tape procedure is an ideal treatment for the obese patient. Am J Obstet Gynecol 189:1601-1604

14. Alcalay M, Monga A, Stanton SL (1995) Burch colposuspension: a 10-20 year follow-up. Br J Obstet Gynaecol 102: 740-745

15. Tsivian A, Mogutin B, Kessler O, Korczak D, Levin S, Sidi AA (2004) Tension-free vaginal tape (TVT) procedure in the treatment of female stress urinary incontinence: long-term results. J Urol 173:998-1000

16. Nilsson CG, Kuuva N, Falconer C, Rezapour M, Ulmsten U (2001) Long-term results of the tension-free vaginal tape (TVT) procedure for surgical treatment of female stress urinary incontinence. Int Urogynecol J Pelvic Floor Dysfunct 12 (Suppl):S5-S8

17. Tsivian A, Kessler O, Mogutin B, Rosenthal J, Korczak D, Levin S et al (2004) Tape related complications of the tensionfree vaginal tape procedure. J Urol 171:762-764

18. Chung MK, Chung RP (2002) Comparison of laparoscopic Burch and tension-free vaginal tape in treating stress urinary incontinence in obese patients. JSLS 6:17-21

19. Mukherjee K, Constantine G (2001) Urinary stress incontinence in obese women: tension-free vaginal tape is the answer. Br J Urol 88:881-883

20. Rafii A, Darai E, Haab F, Samain E, Levardon M, Deval B (2003) Body mass index and outcome of tension-free vaginal tape. Eur Urol 43:288-292 